\title{
Risk and benefits of temporary pacemaker electrodes in adult open-heart surgery-a systematic review
}

\author{
Malene S. Enevoldsen ${ }^{1,2^{*}}$, Per Hostrup Nielsen ${ }^{1}$ and J. Michael Hasenkam ${ }^{1,3}$
}

\begin{abstract}
Background: To assess the achieved risk and benefits of inserting temporary epicardial pacemaker electrodes after open-heart surgery for potential treatment of postoperative cardiac arrhythmias, and to investigate the extent of its use in clinical practice.

Main text: A systematic search was conducted in PubMed and repeated in Embase and Scopus using the PRISMA guidelines. The search identified 905 studies and resulted in 12 included studies, where the type of surgery, study design, total number of included patients, number of patients having temporary pacemaker electrodes inserted, number of patients requiring temporary pacing, primary reason for pacing, significant factors predicting temporary pacing, registered complications and study conclusion were assessed. Eight papers concluded that routine insertion of temporary pacemaker electrodes in all postoperative patients is unnecessary. One paper concluded that they should always be inserted, while three papers concluded that pacing is useful in the postoperative period, but did not recommend a frequency of which they should be inserted.
\end{abstract}

Conclusions: The literature suggests that the subgroup of younger otherwise healthy patients without preoperative arrhythmia having isolated coronary artery bypass grafting surgery or single valve surgery should not routinely have temporary pacemaker electrodes inserted.

Keywords: Temporary cardiac pacing, Temporary myocardial electrodes, Temporary pacing, Postoperative pacing

\section{Background}

Temporary pacemaker electrodes are deployed in the epicardial in most open-heart surgical procedures as a safety precaution to mitigate postoperative arrhythmias which are frequent complications to open-heart surgery $[1,2]$. Postoperative pacing can be instituted to alleviate conduction abnormalities, terminate tachycardia or as prophylaxis in case of, e.g., bradycardia. Hence, temporary pacemaker electrodes offer an opportunity to prevent and treat temporary heart-rhythm disturbances and to improve hemodynamics if needed after open-heart

\footnotetext{
${ }^{*}$ Correspondence: mse@clin.au.dk

${ }^{2}$ Aarhus University, Palle Juul-Jensens Boulevard 99, 8200 Aarhus, Denmark

Full list of author information is available at the end of the article
}

surgery [3]. It is therefore a wide used procedure with a reported low rate of complications [4]. However, even though complications are reported rare, they can be of severe character counting myocardial damage, bleeding and tamponade, infection, perforation, disruption of coronary anastomosis and migration of remaining electrodes after incomplete extraction [3,5]. It is common knowledge that temporary pacemaker electrodes cause problems during extraction and a frequently used counter measure is to cut the electrode flush with the skin. In a review from 2012 [5], complications to cutting temporary pacemaker electrodes flush with the skin were assessed, and they reported incidents of herniation of intraabdominal structures through a diaphragmatic defect created by a retained electrode, hematoma surrounding a retained electrode compressing the right atrium, migration to 
the bronchial tree and abscess formation among others. Hence, the procedure is not as simple as may firstly assumed, and many surgeons with years of experience and a large repertoire of cardiac surgeries, can most likely report of cases with adverse events to the insertion of temporary pacemaker electrodes. Of public known cases is the death of former astronaut Neil Armstrong [6].

The routine use of temporary pacemaker electrodes builds on recommendations made decades ago [7] and may not reflect the current existing surgical techniques and operating practice. Well-defined guidelines on the use of temporary pacing after cardiac surgery, i.e., specific patient groups, type of surgery, or pre- or perioperative cardiovascular monitoring values have not been outlined and published [8]. This is emphasized by the fact that most postoperative arrhythmias are medically treated; thus, it is unclear how often the temporary pacing electrodes are crucial for treatment. In addition, it is a procedure which is routinely conducted, but in our experience, rarely registered in the patient records. Despite the relevance of investigating how often temporary pacemaker electrodes are used for post-operative pacing compared to the insertion rate, surprisingly few papers have been published recently on this topic.The hypothesis for this systematic literature review was that too many patients are having temporary pacemaker electrodes inserted, compared with the number of patients of who actually benefit from temporary pacemaker electrodes. The aim of this study therefore, by a literature review is to assess the use of temporary pacemaker electrodes and potentially disclose predicting factors for need of postoperative pacing.

\section{Main text}

\section{Information sources and search strategy}

A systematic literature search was performed using the database PubMed and repeated in Embase and Scopus. The last date of search was August 2, 2021.

The applied search strategy was "ventricular pacing wires OR temporary pacing wires OR TEPW". In PubMed the search strategy was extended by "((("Cardiac Pacing, Artificial"”[Mesh])) AND (temporary postoperative pacing))" to include MESH-terms. To ensure a broad inclusion "epicardial" and "myocardial" were used synonymously. No review protocol was made before the study.

\section{Study selection}

The literature search and selection was performed by the first author, and verified by the co-authors, and all studies were consequently reviewed, and PRISMA guidelines [9] were followed and reported (Fig. 1).

\section{Eligibility criteria}

Studies were eligible if they assessed whether a group of adult patients benefitted from having epi- or myocardial pacing electrodes inserted as a part of open-heart surgical procedures. Studies concerning transvenous-, transcutaneous-, transesophageal-, or transthoracic pacing were excluded. Studies only comparing different subtypes of pacing were excluded. Studies focusing only on atrial pacing for prevention of atrial fibrillation without depicting the type of cardiac surgery were excluded. Studies concerning congenital cardiac surgery alone were also excluded. The search included all types of studies apart from case reports. Studies were limited to articles published in English language between year 1980 and 2021.

\section{Data collection process}

The following information was obtained from each study: author, year of publication, type of surgery, study design, total number of included patients, number of patients having temporary pacemaker electrodes inserted, number of patients requiring temporary pacing, primary reason for pacing, significant factors predicting temporary pacing and conclusion.

\section{Quality assessment}

The methodological quality of the included studies was assessed using the National Heart, Lung and Blood Institute's checklists [10]. Studies were considered of good quality if $60 \%$ or more of the criteria were met in the respective assessment tools. The individual assessments can be found in Additional file 1: Appendix 1. The studies were further assessed using the Effective Public Health Practice Project Quality Tool (EPHPP) [11, 12] (Additional file 1: Appendix 2). Selection bias, study design, confounders, blinding, data collection and withdrawals and drop-outs were scored to be either "weak," "moderate," or "strong," resulting in a global rating to be either "weak," "moderate," or "strong." Studies were rated "strong" if they received no "weak" scores, "moderate" if it received one "weak" score, and "weak" if it received more than one "weak" score.

\section{Outcomes and prioritization}

The aim was to identify studies reporting the use of temporary pacemaker electrodes and to investigate the extent of this use in clinical practice. Only studies with outcomes directly addressing number of patients receiving postoperative temporary pacing were included. 


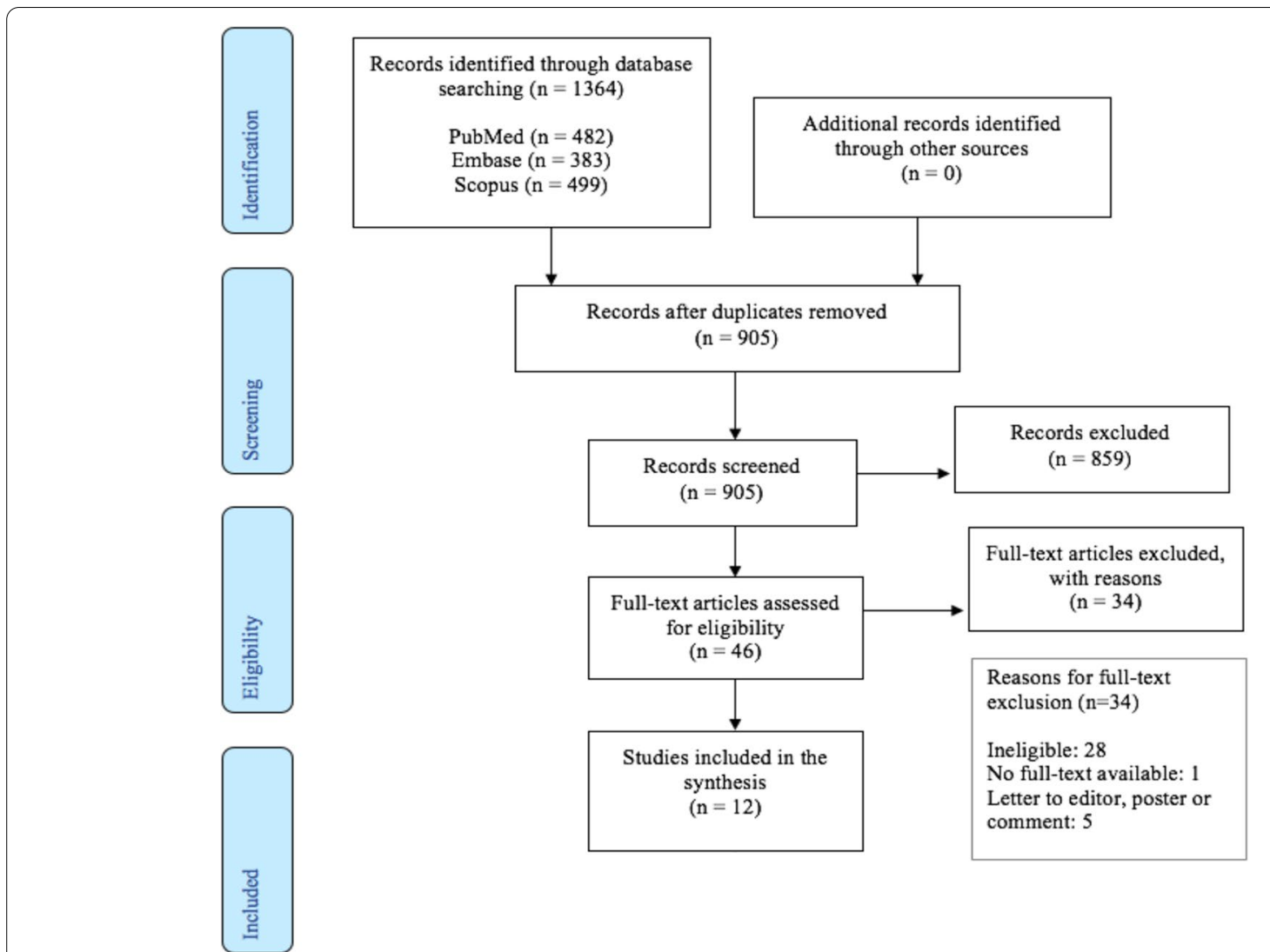

Fig. 1 PRISMA' 2009 flow diagram. The PRISMA flow diagram shows the details in the data selection progress. ${ }^{1}$ Preferred Reporting Items for Systematic Reviews and Meta-Analyses

\section{Results for selection of studies}

The established database revealed 1.364 studies. The search identified 274 and 208 (MESH) results in PubMed, 383 results in Embase, 499 results in Scopus, and 0 in grey literature searches. After duplicates were removed, the number was reduced to 905 studies, of which 859 were excluded in the title and abstract screening due to eligibility criteria. Of the remaining 46 studies, 33 were excluded in the full-text screening due to eligibility criteria and type of paper. One study [13] were excluded since it was not possible to trace down the full-text online or by the Royal Danish Library, or the full-text was unsuccessfully requested by authors through ResearchGate.net. Hence, a total of 12 studies were included in the review (Table 1).

\section{Results for study characteristics}

The study material comprised five retrospective observational studies [14-18], six prospective observational studies [7, 19-23], and one systematic review [24]. The individual study designs were not further labeled. Alwaqfi [14], Abd Elaziz [15], and Ferrari [18] investigated the frequency of pacing among valve operated patients, while Bethea [19], Puskas [20], Imren [22], Asghar [21], and Khorsandi [24] focused on pacing after coronary artery bypass grafting (CABG) surgery. Cote [17], Kiely [23], Morin [7], and Takeda [16] included both CABG, valve surgery, and other procedures. Study design, type of surgery, total number of patients, number of patients having temporary pacemaker electrodes inserted, number of patients requiring temporary pacing, primary reasons for pacing, and conclusion are reported in Table 1 . None of the studies reported on inclusion of patients subjected to minimal invasive surgery or aortic root surgery.For most of the studies, patients were grouped according to insertion or non-insertion of temporary pacemaker electrodes, and were additionally subdivided according to the need for postoperative pacing.AlWaqfi [14] and Morin [7] inserted temporary pacemaker electrodes based on an individual evaluation, while other authors [15, 20, 22] had clearly stated criteria for temporary pacemaker electrode insertion. Hence, Abd Elaziz did not insert temporary pacemaker electrodes in patients with (1) young age with no preoperative history of risk factors, (2) isolated single valve replacement with minimal 


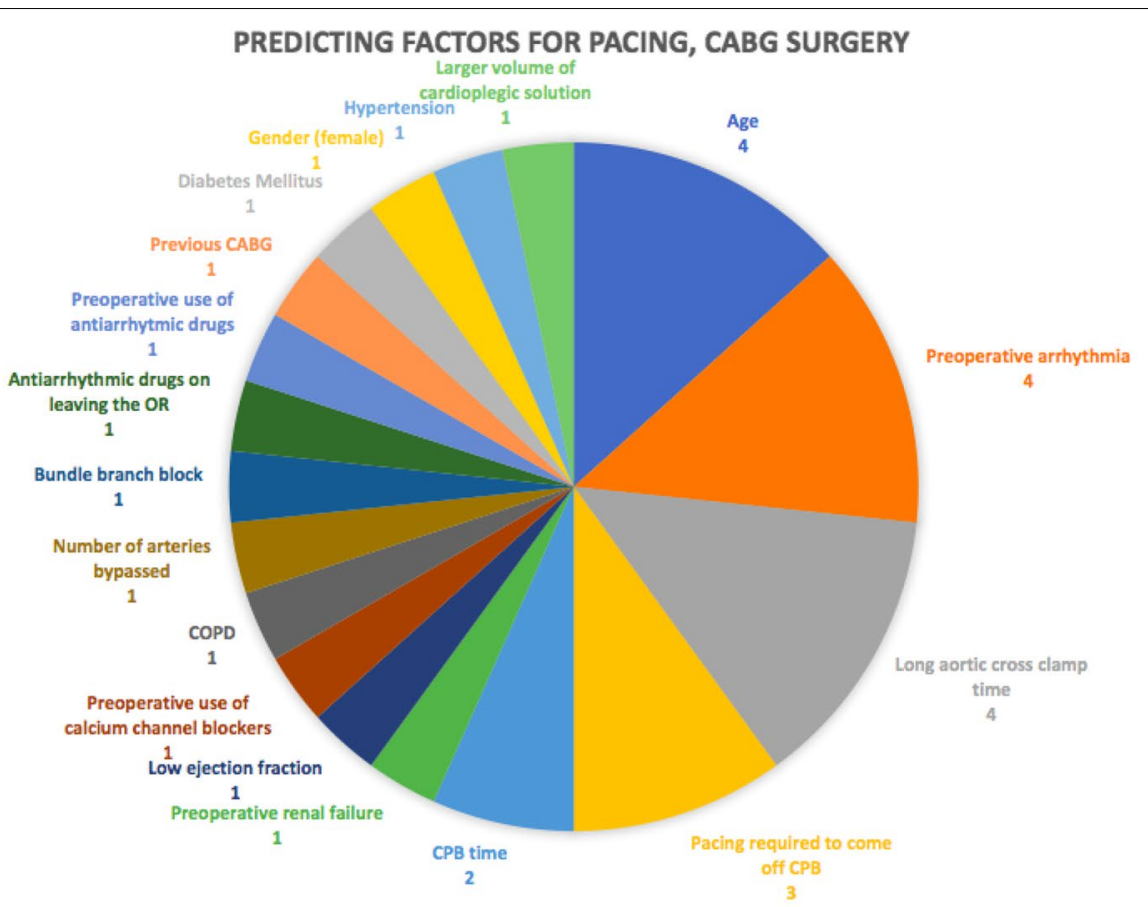

PREDICTING FACTORS FOR PACING, VALVE SURGERY

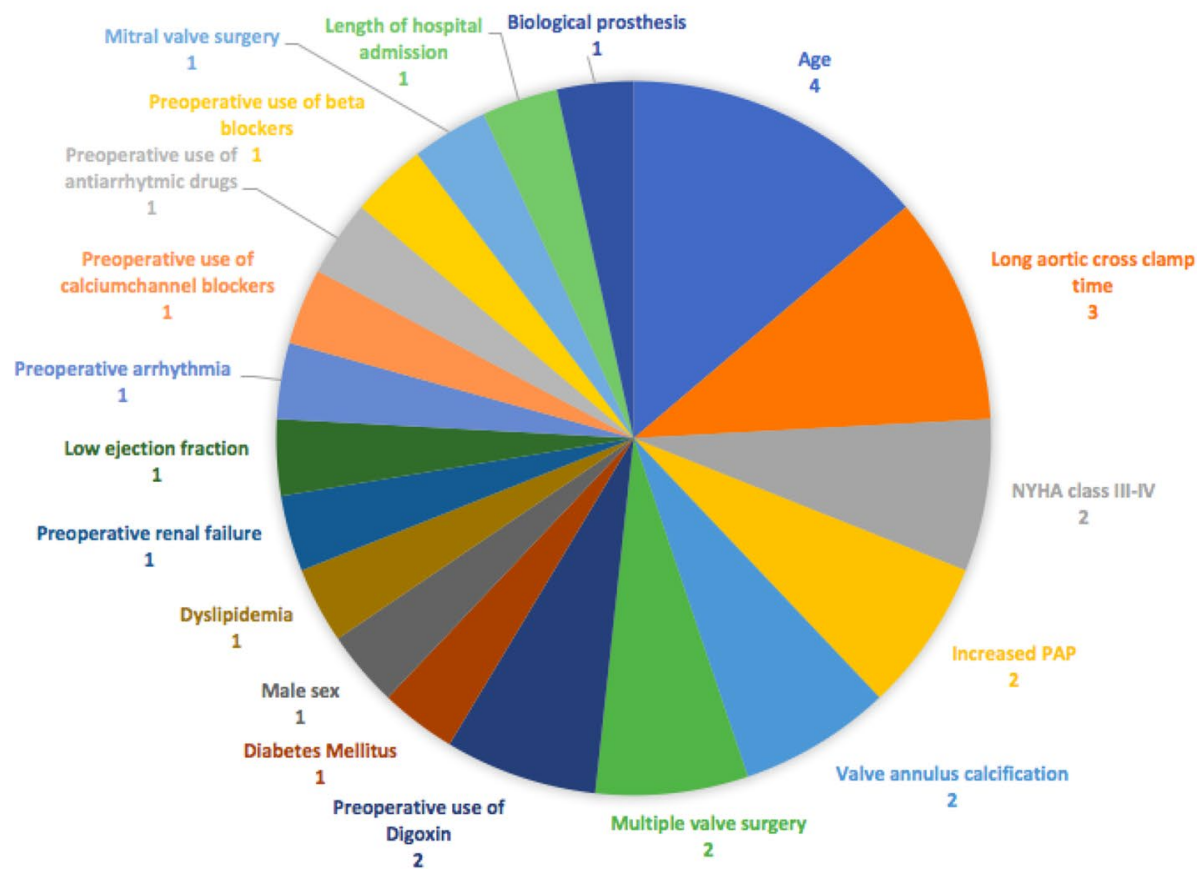

Fig. 2 Number of studies reporting the different significant factors associated with temporary postoperative cardiac pacing

calcification, or (3) easy weaning from cardiopulmonary bypass and stable vital parameters on minimum inotropic support.Puskas [20] inserted temporary pacemaker electrodes if the patients required pacing prior to chest closure.Asghar [21], Bethea [19], Takeda [16],
Cote [17], Ferrari [18], and Kiely [23] inserted temporary pacemaker electrodes in all patients and assessed the need for pacing afterwards. The year of publication ranged from 1982 to 2020. 


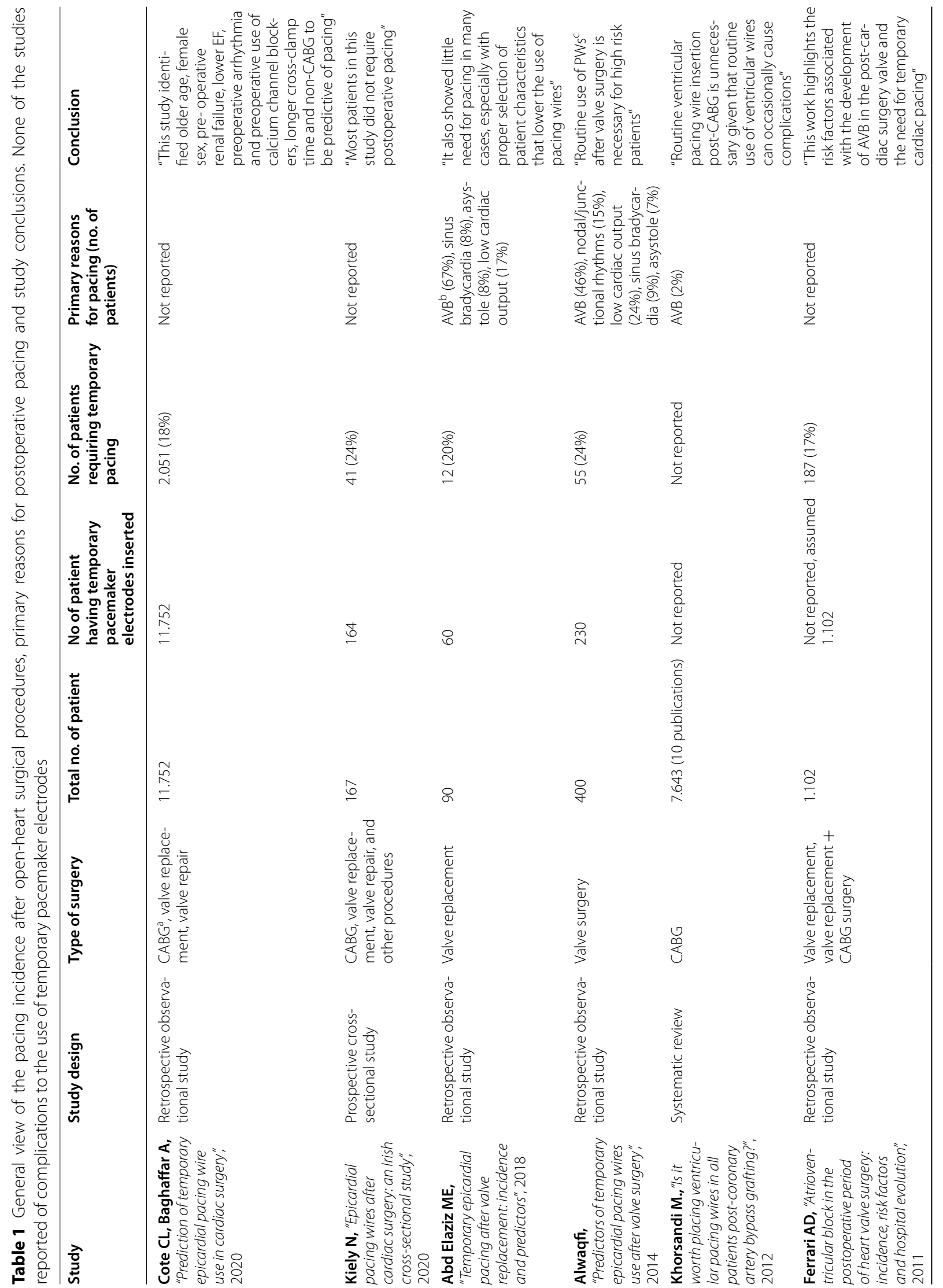




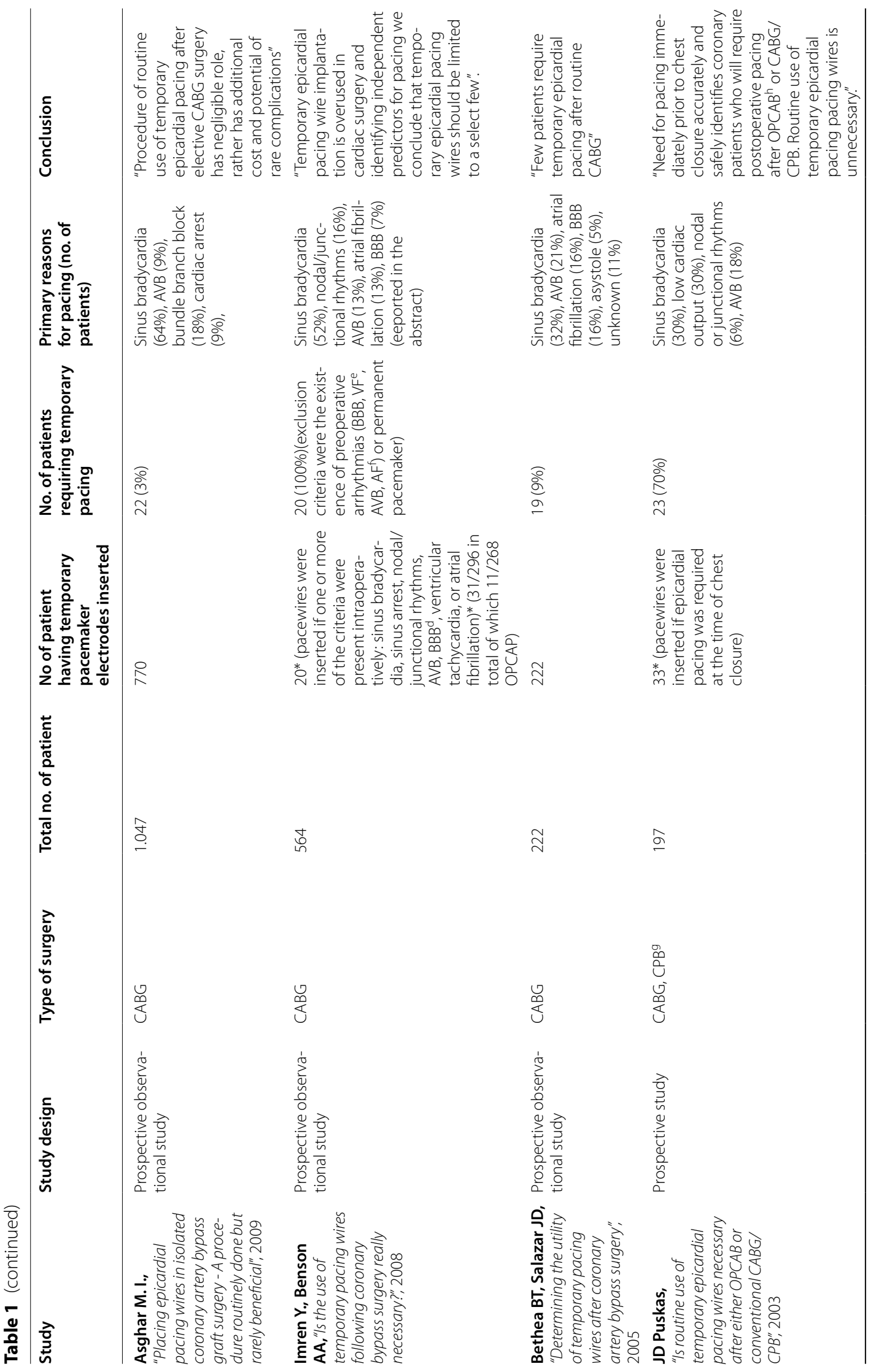




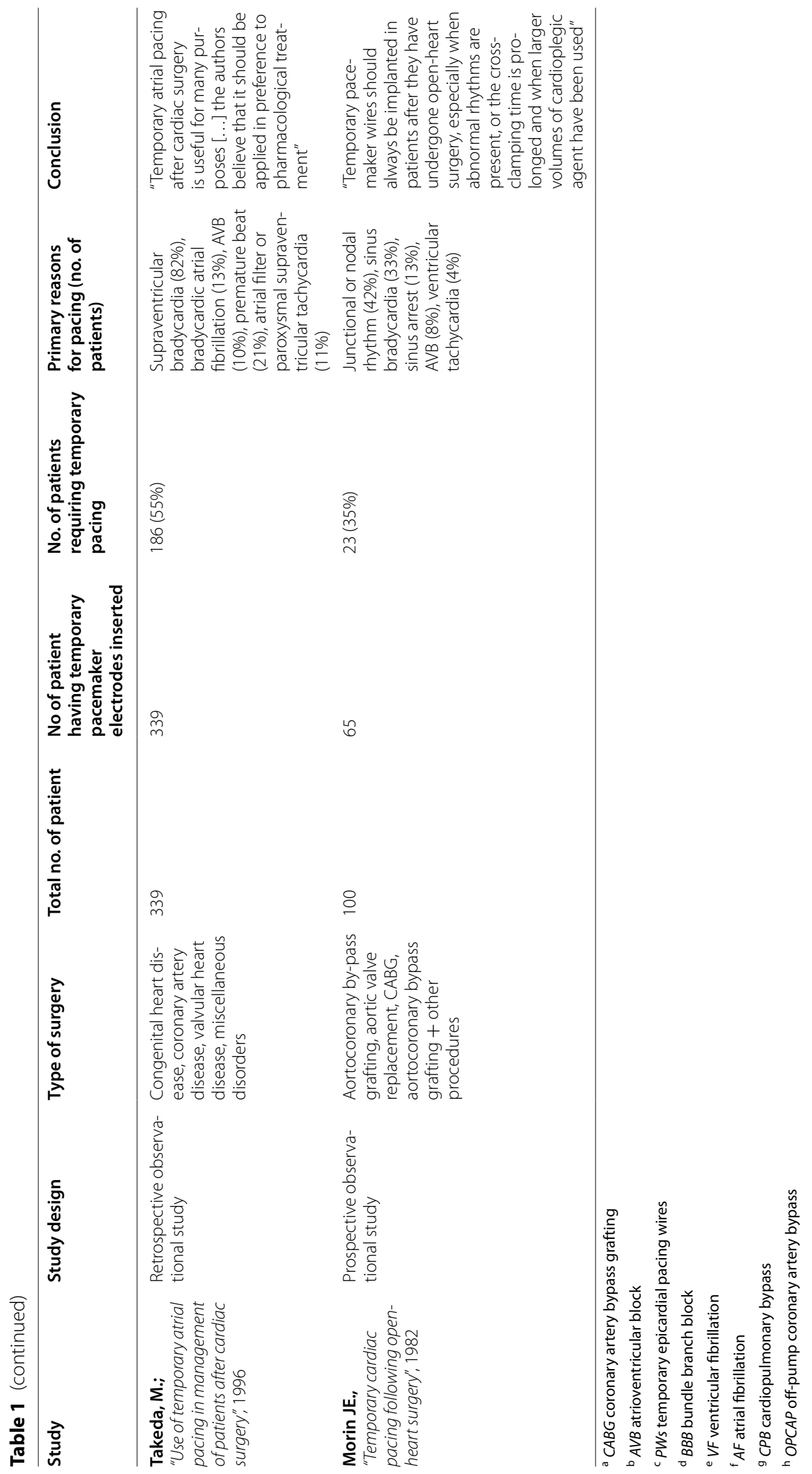




\section{Primary reasons for postoperative pacing}

The most frequent reasons for postoperative pacing were bradycardia (30-82\%) and atrioventricular block (4667\%) (Table 1). Junctional rhythm was the most common reason for postoperative pacing in Morin et al's study [7] with a frequency of $42 \%$ and were reported as a primary reason for pacing for Alwaqfi, Puskas and Imren [14, $20,22]$ as well.Other reported reasons for postoperative pacingwere low cardiac output $[14,15,20]$, asystole $[7$, $14,15,19,21]$, atrialfibrillation $[16,19,22]$, and bundle branch block [19, 21, 22].

\section{Postoperative pacing}

Except from the review publication, the studies included a total of 15.980 patients. Of these, 14.757 patients had temporary pacemaker electrodes inserted and 2.639 (18\%) required pacing in the postoperative period (Table 1). From this latter group, 64 patients [20, 22] only had temporary pacemaker electrodes inserted if pacing was required at the time of chest closure or if arrhythmias occurred intraoperatively. Hence, the two studies found a higher pacing rate $(70 \%, 100 \%)$ compared with the remaining studies where the pacing rate ranged from 3 to $35 \%$.

The studies, where only valve surgery patients were studied $[14,15,18]$ found a higher pacing rate $(24 \%, 20 \%$, $17 \%)$ compared with the two remaining studies where only coronary artery bypass grafting surgery patients were included [19, 21] (3\% and 9\%). Kiely [23] found that $26 \%$ required pacing in the aortic valve repair group, while this number was $25 \%$ in the non-aortic valve repair group.

Imren [22] assessed the need for pacing between onpump and off-pump CABG patients and found that 31 patients need pacing, of which 20 were on-pump patients and eleven were off-pump operated patients.The number of the patients not receiving temporary pacemaker electrodes but requiring pacing in the postoperative period was one and two respectively [7, 22], equivalent to $3 \%$ and $0.3 \%$. Puskas [20] reported that none of the patients in whom temporary pacemaker electrodes were not inserted developed a need for pacing nor suffered any complications due to the absence of temporary pacemaker electrodes. The remaining studies did not address this issue.

\section{Predictors for need of postoperative pacing}

Besides studying the frequency of pacing, most studies also investigated factors predicting the need for postoperative pacing (Table 2, Fig. 2). Predicting factors were not assessed for Takeda [16] and Kiely [23], while Khorsandi [24] did not report the level of statistical significance.For two of the studies reporting on valve surgery $[14,15]$ the factors which were statistically significant associated with temporary cardiac pacing were age, New York Heart Association (NYHA) class III-IV, pulmonary artery pressure $\geq 45 \mathrm{mmHg}[15] / \geq 50 \mathrm{mmHg}$ [14], preoperative use of digoxin, multiple valve surgery, aortic cross-clamp time $\geq 60 \mathrm{~min}[14] / \geq 65 \mathrm{~min}$ [15] and annulus calcification. Ferrari [18] found age $>60$ years, mitral valve surgery, biological prosthesis, length of hospital stay, preoperative antiarrhythmic drugs and $\beta$-blocker to be predisposing factors for atrioventricular block and temporary cardiac pacing.For the CABG surgery studies [19-22], the most frequent factors included preoperative arrhythmias, long aortic cross-clamp time, pacing required to wean from cardiopulmonary bypass, and time on cardiopulmonary bypass appearing at three out of six studies. Older age was a predicting factor in two of the studies, and use of antiarrhythmic drugs upon leaving the operating room, previous CABG surgery, number of coronary arteries bypassed, gender, and hypertension were statistically significant predicting factors in one of the six studies.

Morin [7] and Cote [17] studied multiple types of surgeries and disclosed aortic cross-clamp time, preoperative arrhythmia, preoperative renal failure, low ejection fraction, and preoperative use of calcium channel blocker as predicting factors for use of postoperative pacing. Larger volume of cardioplegic solution was also reported as a predicting factor. This is supported by the study of Imren [22], which found that almost twice as many onpump CABG operated patients as off-pump operated patients were paced.

Digoxin is used in the treatment of atrial flutter, why this factor is an expression for preoperative arrhythmia. Age, preoperative arrhythmias and long aortic crossclamp time were the most frequent predicting factors throughout all the studies (Table 2).

Ashgar found that $1 \%$ of patients required temporary cardiac pacing following standard isolated $C A B G$, if the following three main predictors were addressed before hand: Bundle branch block, pacing when weaning from cardiopulmonary bypass and use of antiarrhythmic upon leaving the operation room.

\section{Routine use of temporary pacemaker electrodes?}

Of the 12 included studies, eight concluded that it is unnecessary to routinely place temporary pacemaker electrodes in all patients [14, 15, 17, 19-23]. Morin [7] concluded that temporary pacemaker electrodes always should be inserted, while the rest concluded that pacing is useful in the postoperative period, but did not take a stand on the frequency of which temporary pacemaker electrodes should be inserted. Cote [17] found that 14\% 
Table 2 Significant factors associated with temporary postoperative cardiac pacing

\begin{tabular}{|c|c|c|c|c|}
\hline Type of surgery & Article & $\begin{array}{l}\text { Factors significantly associated with } \\
\text { temporary cardiac pacing }(P \text { value } \\
\leq 0.05)\end{array}$ & $P$ value & Odds ratio \\
\hline $\mathrm{CABG}^{\mathrm{a}}$, valve surgery & $\begin{array}{l}\text { Cote CL, Baghaffar A, Tremblay P, } \\
\text { Herman CR., "Prediction of temporary } \\
\text { epicardial pacing wire use in cardiac } \\
\text { surgery", } 2020\end{array}$ & $\begin{array}{l}\text { CABG: } \\
\text { - Age (71-80+ years) } \\
\text { - Preoperative renal failure } \\
\text { - Low ejection fraction } \\
\text { - Preoperative arrhythmia } \\
\text { - Preoperative use of calcium channel } \\
\text { blockers } \\
\text { - COPD } \\
\text { - Aortic cross-clamp time > } 90 \text { min } \\
\text { Aortic valve replacement: } \\
\text { - Age (61-80+ years) } \\
\text { - Male sex } \\
\text { - Dyslipidemia } \\
\text { - Preoperative renal failure } \\
\text { - Low ejection fraction } \\
\text { - Preoperative arrhythmia } \\
\text { - Preoperative use of calcium channel } \\
\text { blockers } \\
\text { - Aortic cross-clamp time > } 90 \text { min } \\
\text { Mitral valve repair: } \\
\text { - Age > } 80 \\
\text { - Obesity } \\
\text { - Smoking history } \\
\text { - COPD } \\
\text { Mitral valve replacement: } \\
\text { - Preoperative arrhythmia }\end{array}$ & $\begin{array}{l}\text { CABG: } \\
-<0.01 \\
-<0.02 \\
-<0.01 \\
-<0.01 \\
-<0.01 \\
-0.04 \\
-<0.01 \\
-<0.01 \\
-<0.01 \\
-<0.01 \\
-<0.01 \\
-<0.01 \\
-<0.01 \\
-<0.01 \\
-<0.01 \\
-<0.01 \\
-0.05 \\
-0.04 \\
-0.01 \\
-0.02\end{array}$ & $\begin{array}{l}\text { CABG: } \\
-2.4 \\
-1.5 \\
-2.7 \\
-1.7 \\
-1.4 \\
-1.1 \\
-1.4 \\
-1.7 \\
-0.7 \\
-0.8 \\
-1.5 \\
-2.5 \\
-2.1 \\
-1.2 \\
-1.7 \\
-61.6 \\
-5.6 \\
-0.3 \\
-10.7 \\
-3.3\end{array}$ \\
\hline $\begin{array}{l}\text { CABG, valve surgery, and other proce- } \\
\text { dures }\end{array}$ & $\begin{array}{l}\text { Kiely N, O'Brien F, Mooney M., "Epicar- } \\
\text { dial pacing wires after cardiac surgery: an } \\
\text { Irish cross-sectional study", } 2020\end{array}$ & - Not reported & - & - \\
\hline Valve surgery & $\begin{array}{l}\text { Abd Elaziz ME, } \\
\text { "Temporary epicardial pacing after valve } \\
\text { replacement: incidence and predictors", } \\
2018\end{array}$ & $\begin{array}{l}\text { - Age }>65 \\
\text { - Diabetes Mellitus } \\
\text { - NYHAC class III-IV } \\
\text { - Preoperative digoxin use } \\
\text { - PAP }>45 \mathrm{mmHg} \\
\text { - Type of surgery (multiple valve surgery) } \\
\text { - Valve annulus calcification } \\
\text { - Aortic cross-clamp time }>65 \text { min }\end{array}$ & $\begin{array}{l}-0.004 \\
-0.005 \\
-<0.001 \\
-<0.001 \\
-<0.001 \\
-0.01 \\
-0.01 \\
0.006\end{array}$ & $\begin{array}{l}-11 \\
-47.6 \\
-6 \\
-115 \\
-141 \\
-6 \\
-7 \\
-19\end{array}$ \\
\hline Valve surgery & $\begin{array}{l}\text { Alwaqfi, Nizar R, } \\
\text { "Predictors of temporary epicardial pacing } \\
\text { wires use after valve surgery", } 2014\end{array}$ & $\begin{array}{l}\text { - Age } \\
\text { - NYHA class III-IV } \\
\text { - PAP > } 50 \mathrm{mmHg} \\
\text { - Preoperative digoxin use } \\
\text { - Type of surgery (multiple valve surgery) } \\
\text { - Aortic cross-clamp time > } 60 \text { min } \\
\text { - Valve annulus calcification }\end{array}$ & $\begin{array}{l}-0.002 \\
-0.008 \\
-0.001 \\
-0.024 \\
-0.021 \\
-0.010 \\
-0.003\end{array}$ & $\begin{array}{l}-1.1 \\
-5.6 \\
-22.0 \\
-8.0 \\
-13.5 \\
-7.8 \\
-7.9\end{array}$ \\
\hline CABG & $\begin{array}{l}\text { Khorsandi M., Ishaq } \mathbf{M}, " \text { "I it worth plac- } \\
\text { ing ventricular pacing wires in all patients } \\
\text { post-coronary artery bypass grafting?", } \\
2012\end{array}$ & $\begin{array}{l}\text { - Number of coronary arteries bypassed } \\
\text { - CPB time } \\
\text { - Aortic cross-clamp time }\end{array}$ & $\begin{array}{l}- \\
-\end{array}$ & $\begin{array}{l}- \\
- \\
-\end{array}$ \\
\hline \multirow{6}{*}{$\begin{array}{l}\text { Valve replacement, valve replacement + } \\
\text { CABG surgery }\end{array}$} & \multirow{6}{*}{$\begin{array}{l}\text { Ferrari AD, "Atrioventricular block in } \\
\text { the postoperative period of heart valve } \\
\text { surgery: incidence, risk factors and hospital } \\
\text { evolution", } 2011\end{array}$} & - Age $>60$ & $-<0.001$ & -1.99 \\
\hline & & $\begin{array}{l}\text { - Preoperative use of antiarrhythmic } \\
\text { drugs }\end{array}$ & -0.026 & -1.86 \\
\hline & & - Preoperative use of beta-blocker & -0.002 & -1.76 \\
\hline & & - Biological prosthesis & -0.039 & -1.59 \\
\hline & & - Mitral valve surgery & -0.002 & -1.76 \\
\hline & & - Length of hospital admission & $-<0.0001$ & -1.03 \\
\hline
\end{tabular}


Table 2 (continued)

\begin{tabular}{|c|c|c|c|c|}
\hline Type of surgery & Article & $\begin{array}{l}\text { Factors significantly associated with } \\
\text { temporary cardiac pacing }(P \text { value } \\
\leq 0.05)\end{array}$ & $P$ value & Odds ratio \\
\hline \multirow[t]{2}{*}{ CABG } & \multirow{2}{*}{$\begin{array}{l}\text { Asghar M. I., } \\
\text { "Placing epicardial pacing wires in isolated } \\
\text { coronary artery bypass graft surgery - A } \\
\text { procedure routinely done but rarely ben- } \\
\text { eficial", } 2009\end{array}$} & - Age & -0.019 & - \\
\hline & & $\begin{array}{l}\text { - Bundle branch block } \\
\text { - Preoperative arrhythmias (especially } \\
\text { bundle branch block) } \\
\text { - Pacing required to come off CPB } \\
\text { - Use of antiarrhythmic drugs on leav- } \\
\text { ing the operating room }\end{array}$ & $\begin{array}{l}-0.00 \\
- \\
-0.00 \\
-0.00 \\
-0.015\end{array}$ & $\begin{array}{l}- \\
- \\
-\end{array}$ \\
\hline CABG & $\begin{array}{l}\text { Imren Y., Benson AA,"Is the use of tem- } \\
\text { porary pacing wires following coronary } \\
\text { bypass surgery really necessary?", } 2008\end{array}$ & $\begin{array}{l}\text { ONCAPf (multivariate analysis) } \\
\text { Preoperative: } \\
\text { - History of arrhythmia } \\
\text { - Use of antiarrhythmic drugs } \\
\text { - Age } \\
\text { - Previous CABG } \\
\text { Intraoperative: } \\
\text { - Mean CPB } \\
\text { - Mean aorta cross clamp time } \\
\text { - Pacing to come off CPB }\end{array}$ & $\begin{array}{l}-0.002 \\
-0.01 \\
-0.05 \\
-0.02 \\
-0.02 \\
-0.01 \\
-0.02\end{array}$ & $\begin{array}{l}-6.9 \\
-3.1 \\
-1.9 \\
-2.1 \\
-2.4 \\
-2.9 \\
-2.7\end{array}$ \\
\hline CABG & $\begin{array}{l}\text { Bethea BT, Salazar JD, } \\
\text { "Determining the utility of temporary } \\
\text { pacing wires after coronary artery bypass } \\
\text { surgery", } 2005\end{array}$ & $\begin{array}{l}\text { - Preoperative arrhythmias } \\
\text { - Pacing required to come off CPB } \\
\text { - Diabetes mellitus }\end{array}$ & $\begin{array}{l}-0.001 \\
-0.01 \\
-0.04\end{array}$ & $\begin{array}{l}-8.7 \\
-4.7 \\
-3.7\end{array}$ \\
\hline CABG & $\begin{array}{l}\text { JD Puskas, } \\
\text { "Is routine use of temporary epicardial } \\
\text { pacing wires necessary after either OPCAB } \\
\text { or conventional } C A B G / C P B \text { ", } 2003\end{array}$ & $\begin{array}{l}\text { - Age } \\
\text { - Gender (female) } \\
\text { - Hypertension }\end{array}$ & $\begin{array}{l}-0.05 \\
-<0.001 \\
-0.013\end{array}$ & $\begin{array}{l}- \\
-4.39 \\
-3.12\end{array}$ \\
\hline $\begin{array}{l}\text { CABG, valve surgery and other proce- } \\
\text { dures }\end{array}$ & $\begin{array}{l}\text { Takeda, M.; Furuse, A.; } \\
\text { "Use of temporary atrial pacing in man- } \\
\text { agement of patients after cardiac surgery", } \\
1996\end{array}$ & - Not reported & -- & - \\
\hline $\begin{array}{l}\text { CABG, valve surgery and other proce- } \\
\text { dures }\end{array}$ & $\begin{array}{l}\text { Morin JE., } \\
\text { "Temporary cardiac pacing following } \\
\text { open-heart surgery", } 1982\end{array}$ & $\begin{array}{l}\text { - Prolonged aortic cross-clamp time } \\
\text { - Larger volume of cardioplegic solution }\end{array}$ & $\begin{array}{l}-0.001 \\
-0.025\end{array}$ & - \\
\hline
\end{tabular}

Abbreviations: ${ }^{1} C A B G$ coronary artery bypass grafting, ${ }^{2} C O P D$ chronic obstructive pulmonary disease, ${ }^{c} N Y H A$ New York Heart Association, ${ }^{\mathrm{d}} P A P$ pulmonary artery pressure, ${ }^{e} C P B$ cardiopulmonary bypass, ${ }^{f} O N C A P$ on-pump coronary artery bypass

of the isolated CABG patients potentially could have avoided temporary pacemaker electrode insertion.

None of the studies reported any severe complications from the use of temporary pacemaker electrodes. However, severe complications have been described in literature, including tamponade and electrode migration [25-27].

\section{Quality assessment of included studies}

With regard to the hierarchy of evidence to reflect questions of effectiveness [28] the studies mostly belonged to the middle, counting observational cohort studies, crosssectional studies and a case-control study. Khorsandi [24] was the only study scoring high in the hierarchy of evidence being a systematic review.

Due to the heterogeneity of the study designs, the studies could not all be assessed using the same tool. Khorsandi [24] was scored following the tool for Systematic Reviews created by the National Heart, Lung and
Blood Institute [10]. It provided quality assessment tools for most study designs, however these checklists are not nearly as comprehensive as the EPHPP tool, why this was used to assess the quality in the remaining studies.

Khorsandi et al. [24] were considered of good methodological quality by fulfilling $>60 \%$ of the National Heart, Lung and Blood Institute's respective checklist [10]. The quality assessment using the EPHPP tool resulted in nine studies $[7,14,15,17-22]$ receiving a strong global rating, and two studies $[16,23]$ receiving a moderate global rating (Additional file 1: Appendix 2).

\section{Selection bias}

To reduce the risk of selection bias, the studies were scored based on how well the study population represented the target population. All the included studies scored "very likely" since the study groups were patients going through different kinds of open-heart surgical procedures, hence fulfilling international standardized 
criteria for the respective surgical procedures [29, 30]. Thus, the study groups were considered homogeneous across the studies and therefore, securing a high external validity.

\section{Study design}

The studies were all categorized to be 'cohort analytics' or 'case-control study' and hence received a moderate rating. The categorization was based on the EPHPP dictionary description, since none of the studies labeled their study design further than being a retrospective or prospective observational or cross-sectional study.

\section{Confounders}

The study group in this review consist of patients varying in age, gender, comorbidities and intraoperative factors, why all the studies scored 'yes' in the question of important differences between groups prior to the intervention. Most of the studies [7, 14, 15, 17-22] analyzed risk factors resulting in a strong score where most of the relevant confounders were controlled. Takeda [16] and Kiely [23] received a weak score, because only few or none of the factors were assessed. None of the studies discussed confounders explicitly in the text, but only addressed the significant associations.

\section{Blinding}

Blinding was not explicitly described in the studies except Puskas [20], and all studies received a moderate score equivalent to 'can't tell' or only partial blinding.

\section{Data collection methods}

Data was estimated to be valid and reliable for all the included studies, since it consisted of objective data retrieved by researchers or medical records.

\section{Withdrawals and drop-outs}

Withdrawals and drop-outs were not explicitly described in the studies, but number of deaths in the early postoperative days was reported by Kiely [23], Imren [22], Asghar [21] and Bethea [19].Imren [22] reported that one patient from the non-paced group developed a need for pacing. It is not elaborated whether any of these patients were withdrawn from the statistics.Alwaqfi [14], Abd Elaziz [15], Takeda [16], Cote [17] and Ferrari [18] received a moderate score due to their retrospective design while the remaining studies received a strong score.

\section{Discussion}

Insertion of temporary epicardial electrodes is performed numerous times every day all over the world. However, it is striking that when assessing the literature for the evidential benefit of this, the literature displays a remarkable paucity.

This fact is underlined in this review, which is the first of its kind to assess the need for postoperative cardiac pacing in adult open-heart surgical procedures at such an extent. The results show that only few patients develop a postoperative need for pacing and that these patients can be identified by assessment of significant operational predicting factors. Hence, it may be possible to prevent potential harmful side effects, which may be rare, but still is present.

\section{Predictors for need of post-operative pacing}

One of the most significant predictors for postoperative pacing was aortic cross-clamp time which was a pronounced factor in six studies [7, 14, 15, 17, 22, 24]. Intuitively, it could be due to the ischemic injury to the conduction system during cardioplegic arrest after prolonged aortic cross-clamp time [15]. If so, it supports the fact that complicated procedures such as multiple valve surgery or multiple coronary bypasses, without the risk in itself, also increases the risk of need for postoperative pacing since the procedures are prolonged. This association may also be reflected by the disclosure of cardiopulmonary bypass time and larger volume of cardioplegic solution as predicting factors.

Pacing required to wean from cardiopulmonary bypass was a significant risk factor in three studies $[19,21,22]$ on CABG patients. Puskas [20] was not included in this enumeration since the study did not include such a stratification of risk factors. However, temporary pacemaker electrodes were only inserted if pacing was required at the time of chest closure, thus indicating that patients were only included if they needed pacing when weaning from cardiopulmonary bypass. This could explain the high number of paced patients (70\%) [20] compared with $3 \%$ [21] and 9\% [19].It seems reasonable to state that older age, preoperative arrhythmia, long aortic crossclamp time, multiple valve or CABG surgery and pacing coming off cardiopulmonary bypass are strong predictors for need of post-operative cardiac pacing. Accordingly, if the patients are young without preoperative arrhythmia having isolated CABG or single valve surgery with a low aortic cross-clamp time and no need for pacing during weaning from cardiopulmonary bypass, this review does not justify the use of temporary pacemaker electrodes since these patients are less likely to benefit from it. And should patients without temporary pacemaker electrodes 
develop postoperative need for cardiac pacing, it is possible to initiate other pacing options, e.g., transvenous pacing [31].

\section{Primary reasons for postoperative pacing}

The most frequent indication for postoperative pacing in the literature was postoperative bradycardia. However even though bradycardia is defined as $<60$ beats/ min [32], it must be assessed for each individual patient. Bradycardia is therefore an inexact indicator for need of pacing, since patients tolerate different heart rates differently. It is a risk that patients may be paced even though their bradycardia is reversible and does not cause hemodynamic impairment. This might affect the internal validity.

Another aspect on bradycardia as indication for postoperative pacing, is the fact that most patients receives $\beta$-blockers prior to cardiac surgery. The reasoning is to reduce morbidity and illness progress and increase ejection fraction. However, $\beta$-blockers may also induce bradycardia and hypotension. Hence, the risk to create a medically induced bradycardia, resulting in an increased per- and postsurgical "need" for pacing. Five studies [14, $15,19,21,22]$ did however assess this association and found no significant correlation between the preoperative use of $\beta$-blocker and postoperative need for pacing.

On the other hand preoperative use of digoxin was a predicting factor for postoperative pacing in Alwaqfi's [14] and Abd Elaziz's [15] studies. Similar to the issue of $\beta$-blockers, digoxin prolongs the AV-node refractory period, thereby increasing the need for postoperative pacing [33]. The use of digoxin may also reflect the presence of preoperative arrhythmia, thus making preoperative arrhythmia the most frequent predicting factor for postoperative pacing. Another important factor in impairing the myocardial constriction after pulmonary bypass is hypothermia. Hypothermia is advantageous by decreasing myocardial oxygen demand, but has been questioned for impairing the myocardium's homeostatic processes. In the included studies, hypothermia may be implicit in the time on cardiopulmonary bypass or the given cardioplegic solution. However, it could be relevant to further explore and elaborate hypothermia in general during open-heart surgery, also in relation to the debate of warm versus cold cardioplegia [34].

\section{Routine use of temporary pacemaker electrodes?}

Complications related to the use of temporary pacemaker electrodes include arrhythmia, infection, damage to the myocardium, perforation and tamponade [3].
Why extraction is performed gently, eventually with ECG monitoring, and followed by an observational period.

In the included studies, complications to the use of temporary pacemaker electrodes, bleeding included, were in general reported none [20,21, 23] or rare [22]. Only Imren [22] reported complications in the form of temporary pacemaker electrodes being cut flush with the skin and left in two patients. This supports the general consideration that the use of temporary pacemaker electrodes is a safe procedure and low morbidity and mortality can be allocated to the use of temporary pacemaker electrodes. Why this review's recommendation to be more selective in temporary pacemaker electrodes insertion build upon an excessive use rather than an attendant risk. The lack of guidelines is problematic because the insertion of temporary pacemaker electrodes becomes based on the individual surgeon's discretion and not based on evidence based medicine. Although inserting temporary pacemaker electrodes is a simple procedure in accordance with the non-maleficence principle, it is essential to standardize all procedures to disclose and minimize adverse events. Furthermore, no surgical procedure is risk-free. Hence, the relevance for addressing the lack of national guidelines, and the need for the present systematic literature review regarding the use of temporary pacemaker electrodes. Only few patients require temporary cardiac pacing following routine CABG [19-22, 24], and the results are similar for patients having valve surgery, where the need for pacing is low in many cases and therefore mainly should be offered high risk patients $[14,15]$. It is interesting that if the three main predictors were addressed, Ashgar and Bethea reported the need for pacing among isolated CABG patients as low as $1 \%$ and $3 \%$. Hence the percentage of patients in need of pacing, if addressed for significant factors, is firstly very low, and secondly, close to the rate of complications to temporary pacemaker electrode insertion which is reported to be $0.09-0.4 \%[4,35]$. This underlines the relevancy of discussing the indications for temporary pacemaker electrode insertion, and questions whether routine insertion generates a significant benefit compared to the costs and risks; as emphasized by Kiely et al. [23]. Because a procedure with a benefit-percentage so close to the percentage of complications naturally gives rise to criticism and should not be considered standard operating practice.

\section{Limitations of the included studies}

The studies were in general limited by small sample sizes and inherent design of observational studies where patients were not prospectively randomized to receive temporary pacemaker electrodes or no electrodes. 
Furthermore, the study results are based on per-protocol basis rather than intention to treat.Only five studies reported the number of complications, of which none further elaborated the consequences of such complication.

Cote et al did not explicitly report and quantify the exact number of patients receiving temporary pacing electrodes, but based on the description, it is a fair assumption that all the included patients had electrodes inserted.

\section{Limitations of this review}

The limitations of this review, includes only selecting studies in a limited number of languages, making the review sensitive to possible language bias.Publication bias may also be present. There is a risk that researchers who found an actual need for routine insertion of temporary pacemaker electrodes, thus confirming clinical practice as of today, did not publish their findings-or the medical journals rejected to publish such studies.

\section{Study quality}

Study design was not considered in the inclusion criteria, and none of the included studies were performed as prospective randomized controlled studies. Despite the type of studies, none of the included studies received a global rating lower than moderate.

This review draws a clear pattern in the need for postoperative cardiac pacing based on patient characteristics. Underlining the issue in routine temporary pacemaker electrode insertion when predicting factors is evidently described in recent scientific publications. The present literature review provides a convincing basis for conducting a larger prospective randomized study on routine use versus use of temporary pacemaker electrodes on specific indications. Firstly, to confirm and conclude these findings and secondly to form the basis for extensive temporary pacemaker electrode insertion guidelines in agreement with evidence based medicine.

\section{Conclusions}

Only few patients with temporary pacemaker electrodes inserted required pacing in the postoperative period. The frequency of complications and other unexpected side effects caused by temporary pacing electrodes are poorly reported. This highlights the need for guidelines addressing insertion of temporary pacemaker electrodes. Specific factors predict the need for postoperative pacing including age, NYHA class III-IV, increased pulmonary artery pressure, preoperative arrhythmia, multiple valve surgery, long aortic cross-clamp time, annulus calcification, pacing required to wean from cardiopulmonary bypass, diabetes mellitus, and use of antiarrhythmic drugs on leaving the operation room. Our findings, though based upon observational studies, suggest that the subgroup of younger otherwise healthy patients without preoperative arrhythmia having isolated CABG or single valve surgery are less likely to develop a postoperative need for pacing. Since complications associated with temporary pacing electrodes are most likely underreported and we need larger prospective studies on the risk and benefits of the use of temporary pacemaker electrodes.

\section{Abbreviations \\ CABG: Coronary artery bypass grafting; EPHPP: Effective Public Health Practice Project Quality Tool; MeSH: Medical Subject Headings; NYHA: New York Heart} Association.

\section{Supplementary Information}

The online version contains supplementary material available at https://doi. org/10.1186/s43057-021-00064-1.

Additional file 1.

\section{Acknowledgements}

Not applicable.

Authors' contributions

M.E. provided the concept, design and script of the study, along with acquisition, analyses and interpretation of the data. J.M.H. provided data interpretation, critical revision of the study for important intellectual content and approved the version to submission. P.H.N. provided guidance, critical revision of the study for important clinical content and approved the version to submission.

Funding

The study was not funded.

Availability of data and materials

The data and material are available at PubMed, Embase, and Scopus as of August 2, 2021.

\section{Declarations}

Ethics approval and consent to participate Not applicable.

Consent for publication

Not applicable.

Competing interests

The authors declare that they have no competing interests.

\section{Author details}

${ }^{1}$ Department of Cardiothoracic and Vascular Surgery, Aarhus University Hospital, Aarhus, Denmark. ${ }^{2}$ Aarhus University, Palle Juul-Jensens Boulevard 99, 8200 Aarhus, Denmark. ${ }^{3}$ Department of Clinical Medicine, Aarhus University, Aarhus, Denmark.

Received: 19 October 2021 Accepted: 19 December 2021

Published online: 13 January 2022 


\section{References}

1. Creswell LL, Schuessler RB, Rosenbloom M, Cox JL (1993) Hazards of postoperative atrial arrhythmias. Ann Thorac Surg 56(3):539-549

2. Frank E Silvestry M. Postoperative complications among patients undergoing cardiac surgery: UpToDate; 2019 [Available from: https://www. uptodate.com/contents/postoperative-complications-among-patientsundergoing-cardiac-surgery.

3. Reade MC (2007) Temporary epicardial pacing after cardiac surgery: a practical review: part 1: general considerations in the management of epicardial pacing. Anaesthesia. 62(3):264-271

4. Del Nido P, Goldman BS (1989) Temporary epicardial pacing after open heart surgery: complications and prevention. J Card Surg 4(1):99-103

5. Shaikhrezai K, Khorsandi M, Patronis M, Prasad S (2012) Is it safe to cut pacing wires flush with the skin instead of removing them? Interact Cardiovasc Thorac Surg 15(6):1047-1051

6. Scott Shane SK. Niel Armstrong's death, and a stormy secret \$6 million settlement. The New York Times. 2019;July 24, 2019, Section A, Page 1 of the New York edition with the headline: Public Eulogies To Space Hero Hid a Tempest.

7. Morin JE, Wynands JE, Ralphs-Thibodeau S (1982) Temporary cardiac pacing following open-heart surgery. Can J Surg 25(2):128-131

8. Leonard I Ganz M, FHRS, FACC. Temporary cardiac pacing: UpToDate; 2019 [Available from: https://www.uptodate.com/contents/temporarycardiac-pacing.

9. Moher D, Liberati A, Tetzlaff J, Altman DG (2009) Preferred reporting items for systematic reviews and meta-analyses: the PRISMA statement. PLOS Med 6(7):e1000097

10. Atkins D, Best D, Briss PA, Eccles M, Falck-Ytter Y, Flottorp S, et al. Grading quality of evidence and strength of recommendations. BMJ (Clinical research ed). 2004;328(7454):1490

11. Cilliska D M, S., Dobbins, M., Thomas, B.H. Effective Public Health Practice Project Quality Assessment Tool (EPHPP). 1998

12. Cilliska D M, S., Dobbins, M., Thomas, B.H. Effective Public Health Practice Project Quality Assessment Tool (EPHPP) - Dictionary. 1998.

13. Francis J, Prothasis S, Hegde R, Attia A, Buchan K (2021) Management of temporary epicardial pacing wires in the cardiac surgical patient. Br J Hosp Med (Lond) 82(6):1-7

14. Alwagfi NR, Ibrahim KS, Khader YS, Baker AA (2014) Predictors of temporary epicardial pacing wires use after valve surgery. J Cardiothorac Surg 9:33

15. Abd Elaziz ME, Allama AM (2018) Temporary Epicardial Pacing After Valve Replacement: Incidence And Predictors. Heart Surg Forum 21(1):E049-Ee53

16. Takeda M, Furuse A, Kotsuka Y (1996) Use of temporary atrial pacing in management of patients after cardiac surgery. Cardiovasc Surg 4(5):623-627

17. Cote CL, Baghaffar A, Tremblay P, Herman CR (2020) Prediction of temporary epicardial pacing wire use in cardiac surgery. J Card Surg 35(8):1933-1940

18. Ferrari AD, Sussenbach CP, Guaragna JC, Piccoli Jda C, Gazzoni GF, Ferreira DK et al (2011) Atrioventricular block in the postoperative period of heart valve surgery: incidence, risk factors and hospital evolution. Rev Bras Cir Cardiovasc 26(3):364-372

19. Bethea BT, Salazar JD, Grega MA, Doty JR, Fitton TP, Alejo DE et al (2005) Determining the utility of temporary pacing wires after coronary artery bypass surgery. Ann Thorac Surg 79(1):104-107

20. Puskas JD, Sharoni E, Williams WH, Petersen R, Duke P, Guyton RA (2003) Is routine use of temporary epicardial pacing wires necessary after either OPCAB or conventional CABG/CPB? Heart Surg Forum 6(6):E103-E106

21. Asghar MI, Khan AA, lqbal A, Arshad A, Afridi I (2009) Placing epicardial pacing wires in isolated coronary artery bypass graft surgery--a procedure routinely done but rarely beneficial. J Ayub Med Coll Abbottabad 21(1):86-90

22. Imren Y, Benson AA, Oktar GL, Cheema FH, Comas G, Naseem T (2008) Is use of temporary pacing wires following coronary bypass surgery really necessary? J Cardiovasc Surg (Torino) 49(2):261-267

23. Kiely N, O'Brien F, Mooney M (2020) Epicardial pacing wires after cardiac surgery: an Irish cross-sectional study. Br J Nurs 29(8):476-480

24. Khorsandi M, Muhammad I, Shaikhrezai K, Pessotto R (2012) Is it worth placing ventricular pacing wires in all patients post-coronary artery bypass grafting? Interact Cardiovasc Thorac Surg 15(3):489-493
25. Sugiyama K, Koizumi N, Nishibe T, Ogino H (2018) Catheter intervention to treat migrated temporary epicardial pacing wire into the left side of the heart. Interact Cardiovasc Thorac Surg 27(1):142-144

26. Dyal HK, Sehgal R (2015) The catastrophic journey of a retained temporary epicardial pacemaker wire leading to Enterococcus faecalis endocarditis and subsequent stroke. BMJ Case Rep 2015

27. Bashir A, Mustafa HM, Gunning M, Crossley I, Levine A, Wells D (2013) Retained temporary epicardial pacing wires: a rare cause of prosthetic valve endocarditis. J Coll Physicians Surg Pak 23(9):657-659

28. Petrisor B, Bhandari M (2007) The hierarchy of evidence: Levels and grades of recommendation. Indian J Orthop 41(1):11-15

29. Neumann FJ, Sousa-Uva M, Ahlsson A, Alfonso F, Banning AP, Benedetto U et al (2019) 2018 ESC/EACTS Guidelines on myocardial revascularization. Eur Heart J 40(2):87-165

30. Baumgartner H, Falk V, Bax JJ, De Bonis M, Hamm C, Holm PJ et al (2017) 2017 ESC/EACTS Guidelines for the management of valvular heart disease. Eur Heart J 38(36):2739-2791

31. Tjong FVY, de Ruijter UW, Beurskens NEG, Knops RE (2019) A comprehensive scoping review on transvenous temporary pacing therapy. Neth Heart J 27(10):462-473

32. Mason JW, Ramseth DJ, Chanter DO, Moon TE, Goodman DB, Mendzelevski B (2007) Electrocardiographic reference ranges derived from 79,743 ambulatory subjects. J Electrocardiol 40(3):228-234

33. Krum H, Bigger JT Jr, Goldsmith RL, Packer M (1995) Effect of long-term digoxin therapy on autonomic function in patients with chronic heart failure. J Am Coll Cardiol 25(2):289-294

34. Fan Y, Zhang AM, Xiao YB, Weng YG, Hetzer R (2010) Warm versus cold cardioplegia for heart surgery: a meta-analysis. Eur J Cardiothorac Surg 37(4):912-919

35. Cote CL, Baghaffar A, Tremblay P, Herman C (2020) Incidence of tamponade following temporary epicardial pacing wire removal. J Card Surg 35(6):1247-1252

\section{Publisher's Note}

Springer Nature remains neutral with regard to jurisdictional claims in published maps and institutional affiliations.

\section{Submit your manuscript to a SpringerOpen ${ }^{\odot}$ journal and benefit from:}

- Convenient online submission

- Rigorous peer review

- Open access: articles freely available online

- High visibility within the field

- Retaining the copyright to your article

Submit your next manuscript at springeropen.com 